\title{
PERSONAL VIEW \\ Indigenous clients intersecting with mainstream nursing: a reflection
}

\author{
S Trueman \\ James Cook University, Cairns, Queensland, Australia \\ Submitted: 27 November 2015; Revised: 21 September 2016; Accepted: 5 November 2016; Published: 3 March 2017
}

Trueman S

Indigenous clients intersecting with mainstream nursing: a reflection

Rural and Remote Health 17: 3822. (Online) 2017

Available: http://www.rrh.org.au

\section{A B S T R A C T}

Context: Mental health care for Australian Aboriginal and Torres Strait Islander people living in rural and remote locations is delivered primarily by nurses. Culturally safe therapeutic interventions can promote understanding and improve care. Reflective knowledge thinking, writing and practice can support nurses to practice cultural safety.

Issues: Two instances of mental health care for Australian Aboriginal and Torres Strait Islander clients are described in this reflective piece of writing. The care provided in both instances was culturally inappropriate and/or inadequate. I was an agent or observer in both cases, which happened during my employment as a mental health nurse in Australia. The first story, 'the traumatisation of Client A' describes an instance where I, from a place of ignorance, acted without cultural sensitivity and knowledge. I restrained and observed a client in a way that accorded with workplace policy but, at the same time, failed to take into account the circumstances and cultural safety of my client. The second story, 'the misunderstandings about Client B', occurred much later in my career. This time, I engaged with the client, acted with cultural safety, listened to his story and was able to clear up misunderstandings surrounding his presentation to hospital.

Lessons learned: The two events described in this article led me to discover the nurse I was then and the nurse I have become now. In comparing the two events and my level of awareness and understanding of Aboriginal peoples, along with my own actions, I reflect on my own journey of discovery, which has informed and shaped my awareness as a culturally safe and more sensitive nurse.

Key words: Australia, Australian Aborigines, cultural safety, mental health nursing, reflection, reflective practice. 


\section{Context}

Psychiatric nurses play a key role in assessing, caring for and assisting Indigenous mental health clients. A continuing need exists for nurses to adopt culturally safe, psychiatric therapeutic interventions when working with Aboriginal and Torres Strait Islander clients. In this article I detail two inappropriate psychiatric nurse interventions - one of my own and one that I observed - with Indigenous mental health clients and outline the process of reflection that followed. Reflection facilitates the construction of a 'forum of self' whereby a nurse systematically explores meaning and applies newly formed insights to evolving situations. My own support of cultural safety comes from a 'rights movement' paradigm inextricably mixed with social justice and motivated by an understanding of Indigenous history, culture and oppression. The two psychiatric presentations canvassed in this article illustrate a journey of redemption, commencing from a position of no cultural safety, travelling to a ne plus ultra position of awareness. The article concludes with the image of a place that has not yet been called into being within the landscape of Australian health care.

\section{Reflective knowledge}

Recognition of the importance of professional reflective thinking can be traced to Dewey ${ }^{1}$ and was taken up with gusto by Schon, whose phrase 'reflective practice' gained popularity and momentum after the publication of his seminal work The reflective practitioner ${ }^{2}$. Reflective practice can be defined summarily as careful consideration and examination of issues of concern related to an experience ${ }^{3-5}$. 'The intent is to create ... thought from the unclear to the clear, from the unreasoned to the reasoned ... from the unexamined to the examined $^{\prime 6}$. The individual who uses reflection 'is able to unravel a complex situation, see it for what it is, identify ways to ensure it does not happen again, or identify strategies to improve the outcomes in the future ${ }^{17}$. Reflection is related to self and to improving future practice through a retrospective analysis of action.
Reflective writing is accepted as a key component of reflective practice and is central to the notion of learning from experience. Reflective writing is, by its very nature, in the first person and is essentially subjective ${ }^{8}$. The writer focuses on subjectivity - considering thoughts, feelings, emotions and outcomes - leading to subsequent action and practices that are better-informed than previous ones. Callister outlines the benefits of reflective writing, including '... opportunities to define and articulate links between theory and practice with a focus on lived clinical experience, the development of sustained critical thought by increasing conceptual clarity and increased ability to empathise, observe and describe' ${ }^{\prime}$. Thus, in reflective practice, the purpose of reflection is to undertake a process of learning through experience, thereby enabling the individual to develop new insights about the self and professional practice ${ }^{10}$.

Critical reflective thinking includes making connections, which is the ability to move beyond isolated events and develop a more holistic perspective ${ }^{11}$. The reflective practitioner can use singular personal experiences to make more general connections in the wider clinical field environment ${ }^{12-14}$. It is ' $\ldots$ the artistry of combining a professional repertoire with current clinical problems to invent unique responses ${ }^{15}$. Knowledge arising from the process of reflection leads to general and specific understandings and attempts to illuminate that which is universally true by revealing the particular; it is inductive in nature ${ }^{16}$. Teekman identifies three levels of reflective thinking: for action, for evaluation and for critical inquiry ${ }^{3}$. Within this schema there is a level of seepage and overlap, meaning that each level of reflective thought should not be considered separately. In summary, 'reflection is a threefold process comprising direct experience, analysis of our beliefs, values or knowledge about that experience, and consideration of the options which should lead to action as a result of the analysis ${ }^{\prime 17}$.

\section{Cultural safety}

The two stories outlined in this article relate to Indigenous Australian clients. The stories illustrate inappropriate and culturally unsafe nursing practice. A central principle of cultural safety is that professional knowledge and position 
confer power on nurses. For nurses, cultural safety is about understanding one's identity and considering how one legitimates one's place in the world. This is a necessary precursor to learning to work in partnerships ${ }^{18}$. According to Seaton, '... cultural safety involves nurses examining how power is expressed by nurses in communication and in what way power influences the nurse-patient relationship, the healthcare setting and provider organisations ${ }^{\prime 19}$. This requires nurses to reflect upon and examine their attitudes, beliefs and values alongside an analysis of complex issues such as marginalisation, prejudice, discrimination and racism $^{20,21}$.

\section{Issues}

\section{The traumatisation of Client $A$}

At the time of this first story I was in the employ of a large metropolitan psychiatric hospital, assigned the task of admitting clients from a catchment of rural and remote areas. Client A was an Australian Indigenous woman who lived very remotely and was intimately wedded to both her ancestral lands and traditional lifestyle. Client A had very little contact with non-Indigenous people; she did not speak English.

On admission, Client A's accompanying medical and nursing notes outlined her torturous journey. Client A had been involuntary detained and removed from her traditional lands due to displaying episodes of psychotic behaviour. The manner of detention required non-Indigenous police personnel, accompanied by mental health staff, to visit Client A's community and forcibly remove and transport her to the nearest remote hospital, approximately $300 \mathrm{~km}$ away. On arrival, but after a delay, Client A was medically assessed, intravenously sedated and placed on her first plane flight (ever) under restraint for a 3 hour journey to the city. On arrival, Client A was transferred by ambulance under police escort to the only major city general hospital to be medically cleared for admission. Once cleared for admission, the process having taken some four hours, Client A was placed in another ambulance and transferred, again, under police escort, to the psychiatric hospital where I was working.
On arrival, Client A was 'greeted', whilst strapped to a gurney, by myself and nine other personnel including police officers, security, administrative, nursing and medical staff all of whom were non-Indigenous. Client A was afraid, confused and anxious. After the sedation wore off, the female Indigenous elder experienced bouts of agitation, sadness, tearfulness and aggression before terror and despondency set in.

My principal task was to make sure that Client A did not abscond from the 'open ward'. Fundamentally and necessarily, this task meant that I was to keep Client A under constant observation no matter what the circumstances. Showering, toileting, sleeping, eating, dressing, walking, sitting and thinking were to be openly and intimately observed by me. At no stage was I to lose sight of Client A. A non-Indigenous male, I egregiously observed Client A's bathing and toileting - the most intimate and personal of human daily activities.

On a number of occasions, no doubt while experiencing a farrago of emotions, Client A attempted to impulsively flee the ward; she was compellingly motivated to do so by terror and confusion. On each occasion I used varying degrees of physical force to restrain her. I was unable to communicate or speak her language and I could not placate her or address her obvious fear and understandable concerns.

\section{The misunderstandings about Client B}

A more recent experience caused me to reflect again on nurses' ability to work appropriately in a culturally safe manner without racist overtones. I was visiting a small, isolated and remote Indigenous community in the role of a mental health nurse educator. My role was limited to educating staff; I did not have any contact with or clinical responsibilities for clients. The small four-room health clinic was staffed by four non-Indigenous nurses, all of whom were relieving agency staff from overseas and interstate.

I was summoned hurriedly by two frantic nurses wanting me to assess an Australian Indigenous teenager being brought in 
by the police who would be, 'violent, aggressive and probably psychotic'. I was coerced into seeing the client on the basis of being the only available mental health-trained clinician. Approaching the client in the waiting room, I introduced myself and asked whether it was alright with Client B for me to have a 'yarn' about 'how he was going'. Client B was polite, cooperative and somewhat reserved and accepted my invitation to enter a treatment room. It was immediately apparent, from the stale alcohol smell, that Client B had, despite this community being 'dry' (meaning alcohol was prohibited in the area) had been drinking the night before. After a few introductory remarks I brought the conversation around to the information that had been disclosed by the police. I made the following statement:

... the police were called to chase you up because you were wandering around the streets and then out in the bush yelling and shouting very late last night and they were concerned that you were not safe, might harm yourself or had taken something. They said you didn't come back home despite your Mum yelling out for you to.

Client B did not hesitate to explain and responded with obvious genuineness in saying that he was 'ok' and that he had drunk four bottles of spirits with two mates (an Australian colloquialism for 'friends'). He shared with me that his father - a respected elder - died approximately 4 months ago. Client B said, 'When drinking I am very sad and miss my father'. He explained that his yelling had an important purpose: '(I was) calling out to my father's spirit to come from the earth and country and enter my body, to make me strong like my father and make me a good man just like him . Not 'til this happens can I be a man and walk proud like him. It is right and our culture ...'

Client B was not psychotic, violent, aggressive or at risk, nor was he suffering from a mental illness. I appropriately and sensitively brought the consultation to an end and wished Client B the best for the future. When I attempted to speak to staff later, they outwardly dismissed my realistic assessment of the situation; my attempts to discuss cultural safety with them were perfunctorily dismissed.

\section{Lessons learned}

\section{$A$ sad reflection}

Upon reflection I am ashamed about the manner in which both clients were treated. There was not a vestige of cultural awareness, cultural safety or cultural understanding in either situation. Cultural appropriateness was absent from even the most basic and fundamental of nursing interventions. Each scenario describes blatant personal and systemic ignorance and abuse of the most primitive kind. Client A was an Indigenous Australian woman who, without consent, understanding, compassion, engagement and cultural awareness, was subjected, in the most basic of ignorance, to both institutional and systematic traumatisation. The most egregious element was my ignorance and the nescience that I was committing interpersonal racism. Client $\mathrm{B}$ was an Indigenous Australian teenager, subjected to fundamentally judgemental behaviour based purely on race, fuelled by ignorance of Indigenous beliefs and a complete lack of staff members' insight into their own cultural knowledge and beliefs. On one level, their blindness, due to ignorance, was without malice, but on another level it was flagitious.

The reasons I retell the stories of Client A and Client B are twofold. First, they demonstrate starkly a journey of knowledge that started when I was, unwittingly, a bigoted, passive and uninformed racist. Ignorance led me to perpetrate and enforce structural racism in the health system in which I worked and I had no understanding of the process occurring at the time. As a non-Indigenous 40-year-old, middle class, tertiary-educated nurse, my total and complete acceptance and blind ignorance that 'this is how it is, and this is how we care for Indigenous clients' seems almost unbelievable in retrospect.

Second, by recounting the interactions and sharing my embarrassment and disbelief, hopefully, I will connect with nurses and stir their awareness. They might see how they too have been, or are now, lacking in cultural safety. Recounting Client A's story is not just a shameful recount from a member 
of Australia's dominant 'white' society; it is a shocking, perhaps inspirational, way to show other nurses that there may be aspects of themselves and their practices they are accepting without question. These unanalysed assumptions can affect the quality of care given to clients. The story could be a way forward for other nurses to become enlightened. By sharing my experience, I hope individuals will be encouraged to engage in reflective thinking-for-critical-inquiry about cultural safety.

\section{Change through understanding}

As healthcare professionals, nurses need to be sensitive to the complexity of the contemporary positioning of Indigenous people. The rights of empowerment and self-determination necessitate an acceptance that Indigenous people determine the parameters and positions of their own lives. It is no longer acceptable, and certainly not best practice, to impose 'foreign' health services on Indigenous clients who have had no input into their own care. Indigenous clients should not be passive participants subjected to an alien health system.

The nursing profession needs to acknowledge, and individual nurses need to understand, that the physical and mental health of Indigenous clients and communities is directly related to their agency in life. If Indigenous people are to have control over their lives, they must be given the opportunity to individually and collectively participate in systems and decisions affecting their health and wellbeing. This need for engagement and consultation is crucially important for Indigenous clients and other colonised, oppressed and marginalised people who have, historically and often personally, experienced an absence of human agency ${ }^{22}$.

The Indigenous client is a mixed cultural reality. There are not only different expressions of culture but also differing generational and personal histories of oppression. Therefore, [nurses] should be aware that ethnocentric perceptions might further add to continuing oppression. Care must be taken not to impose our own understandings, assumptions, and 'solutions' on the client. ... there should be a preparedness to engage with the Indigenous client and community as a novice in cultural matters; to take advice, to value and enact that advice and direction. ${ }^{22}$

Arising from this line of argument is the need for nurses to develop a critical awareness of self, as individuals and as a professional group. Australian nurses need to recognise and be aware of Australian Indigenous history and cultural difference, and to be culturally safe in their practices. Individually, and as a profession, there has to be greater respect for and embracing of cultural difference. As well, a bedrock of learning for nurses should be an 'understanding of Indigenous history which includes awareness about contemporary Indigenous life and the diversity of Indigenous peoples, so that the [nurse's] own conditioned values, assumptions, and perspectives of social reality are not imposed on others ${ }^{\prime 22}$. A good starting point would be understanding that ' $[t]$ he present plight, in terms of health ... of so many Aborigines must be acknowledged as largely flowing from what happened in the past ... present disadvantage flows from past injustice and oppression ${ }^{23}$.

As a professional nurse, one has to factor into interactions that some Indigenous peoples' cultural values are different to those of mainstream society. According to Dudgeon, '[Nursing] is largely grounded in western culture. It is a value-laden practice. ${ }^{24}$. As nurses we need to be aware that our actions, based on a western biomedical model of health, can reinforce stereotypes and perpetrate inequality and oppression of Indigenous clients. Both stories reveal the dangers of failing to embed Indigenous cultural values into health care. Nurses who fail to reflect on their practice, knowledge and understandings can become mainstream agents of assimilation, oppression and control, while all the time mouthing phrases of cultural safety, awareness and sensitivity. By recognising the difference between rhetoric and reality, nurses could instead act as agents for real and genuine change.

Taylor $^{25}$ describes emancipation as freedom from your own and from other people's expectations of the roles you 'should' play, enabling you to adopt other ways of being. Central to the notion of freedom is the empowerment of the 
individual. Reflection is a way to achieve this empowerment as it 'free(s) practitioners from the taken for granted assumptions and oppressive forces which limit them and their practice'. Taylor ${ }^{25}$ describes this process as a way of 'transforming your world'. For me, it is axiomatic that 'my worlds', before Client A and after Client B, are truly worlds apart.

\section{Conclusion}

My experiential learning through reflective thinking has challenged my personal values and taken-for-granted views, generating conflict and anxiety within me. I had to deliberately and purposefully engage in a 'discourse-withself $^{3}$ in an attempt to make sense of what Client A had been subjected to. After reflection, I was better able to understand and contextualise the dynamics at play when I met Client B. In essence, I had learnt from Client A's experience by selfquestioning about my experience. I gained knowledge that was transferrable to Client B's circumstances; no doubt leading to a better outcome for him. I triumphed over myself as I had educated myself to form more liberal convictions that went against the grain of my inherited ethnocentric attitudes and racist inclinations. The process has been both enlightening and freeing on a personal level.

Nurses must embed respect for contemporary Indigenous culture and an understanding of Australia's Indigenous history and oppression when caring for, and interacting with, Indigenous clients. Nurses need to listen to Indigenous people and respect their cultural values and ways of behaving. This approach to nursing care can be facilitated by working in partnership with Indigenous people (clients) and seeking advice on issues affecting Indigenous lives. This means working together towards the establishment of socio-political structures through which alternative values and beliefs can be put into practice in delivering mental health services and care. I hope that publishing self-reflective articles such as this will hasten change within the nursing profession towards culturally safe practice and lead others to experience a journey of self-discovery. There is a moral pulse to be detected here and it is quite a strong one.

\section{Acknowledgements}

The author wishes to acknowledge the support and guidance of supervisors, Professor Jane Mills (Massey University), Professor Kim Usher (University of New England) and Dr Tanya Park (University of Alberta).

\section{References}

1. Dewey J. How we think: a restatement of the relation of reflective thinking to the education process. New York: Heath \& Co, 1933.

2. Schon D. The reflective practitioner. New York: Basic Books, 1983.

3. Teekman B. Exploring reflective thinking in nursing practice. Journal of Advanced Nursing 2000; 31(5): 1125-1135. https:// doi.org/10.1046/j.1365-2648.2000.01424.x

4. Flavell J. Metacognition and cognitive monitoring: new area of cognitive developmental inquiry. American Psychologist 1979; 34: 906-911. https://doi.org/10.1037/0003-066X.34.10.906

5. Mezirow J. A critical theory of adult learning and education. Adult Education 1981; 32: 3-24. https://doi.org/10.1177/ 074171368103200101

6. Lambright L. Creating a dialogue: Socratic seminars and educational reform. Community College Journal 1995; 65: 30-34.

7. Usher K, Foster K, Stewart L. Reflective practice for the graduate nurse. In: JC Daly (Ed.). Transition in nursing. 2nd edn. Sydney: MacLennan \& Petty; 2008; 275-289.

8. Jasper M. Using reflective writing within research. Journal of Research in Nursing 2005; 10(3): 247-260. https://doi.org/ $10.1177 / 174498710501000303$

9. Callister A. The use of student journals in nursing education: making meaning out of clinical experience. Journal of Nursing Education 1993; 32: 185-186. 
10. Boud D, Keough R, Walker D. Reflection: turning experience into learning. London: Kogan Page, 1985.

11. Fonteyn M, Cahill M. The use of clinical logs to improve nursing students' metacognition: a pilot study. Journal of Advanced Nursing 1998; 24(1): 174-184. https://doi.org/10.1046/j.13652648.1998.00777.x

12. Koch T. Implementation of a hermeneutic inquiry in nursing: philosophy, rigour and representation. Journal of Advanced Nursing 1996; 24(1): 174-184. https://doi.org/10.1046/j.1365-2648. 1996.17224.x

13. Smith B. Ethical and methodological benefits of using a reflexive journal in hermenuetic-phenomenological research. Journal of Nursing Scholarship 1999; 31(4): 359-363. https://doi.org/10.1111/j.1547-5069.1999.tb00520.x

14. Glaze J. Stages in coming to terms with reflection: student advanced nurse practitioners' perceptions of their reflective journeys. Journal of Advanced Nursing 2002; 37(3): 265-272. https://doi.org/10.1046/j.1365-2648.2002.02093.x

15. Saylor C. Reflection and professional education: art, science and competency. Nurse Education 1990; 15(2): 8-11. https:// doi.org/10.1097/00006223-199003000-00006

16. Charon R. Narrative medicine: a model for empathy, reflection, profession and trust. Journal of American Medical Association 2001; 286(15): 1897-1902. https://doi.org/10.1001/ jama.286.15.1897
17. Whitton D, Sinclair C, Barker K, Nanlohy P, Nosworthy M. Learning for teaching: teaching for learning. Melbourne: Thomson Learning, 2004.

18. Jungerson K. Cultural safety: Kawa Whakaruruhan - an occupational safety perspective. New Zealand Journal of Occupational Therapy 2002; 49(1): 4-9.

19. Seaton L. Cultural care in nursing: a critical analysis. Sydney: University of Technology, Sydney, 2010.

20. Bickley J. Priorities for practice: paper presented at the Norman Peryer Forum 25-27 November. NERF Studies in Nursing 1988; 14: 1-8.

21. Ramsden I. Cultural safety and nursing education in Aotearoa and Te Waipounamu. Wellington: Victoria University, 2002.

22. Dudgeon P, Pickett H. Psychology and reconciliation: Australian perspectives. Australian Psychologist 2000; 35(2): 82-87. https: / /doi.org/10.1080/00050060008260328

23. Australian Human Rights Commission. Bringing them Home: Report of the National Inquiry into the Separation of Aboriginal and Torres Strait Islander Children from their Families. Canberra: Australian Human Rights Commission, 1997.

24. Dudgeon P. Indigenous psychologists' stories. InPsych February 2007.

25. Taylor B. Reflective practice: a guide for healthcare professionals. 3rd edn. Maidenhead: Open University Press, 2010. 